\title{
Grants fall victim to NIH success
}

Seven thousand fewer people showed up at this year's Society for Neuroscience meeting than last year. That still left 21,000 researchers attending one of the most popular conferences in biomedicine. But hallway gossip swirled around one possible cause for the drop-off - money, in the form of grants from the US National Institutes of Health (NIH).

"Dollars come to mind," says Jeffrey Rothstein, a neurologist at Johns Hopkins University in Baltimore, Maryland. ${ }^{\text {c }}$ The field has expanded and we now have less money per person."

Rothstein's comments explain an apparent paradox: the annual budget for the $\mathrm{NIH}$ doubled between 1998 and 2003, and now stands at $\$ 28.6$ billion. But many researchers are finding it far more difficult to win grants. This is because universities invested hugely in infrastructure and workforce once the doubling began, which led to an explosive growth in grant applications. In 1998, the NIH received 24,000 grant applications; this year the number is 46,000 and is forecast to reach 49,000 in 2007.

Two other metrics have also changed, helping to create the perfect storm. Average grant sizes have grown by $40 \%$ since the doubling began, from $\$ 275,000$ in 1998 to $\$ 400,000$ today; and Congress has stopped increasing the NIH budget. So the agency's buying power

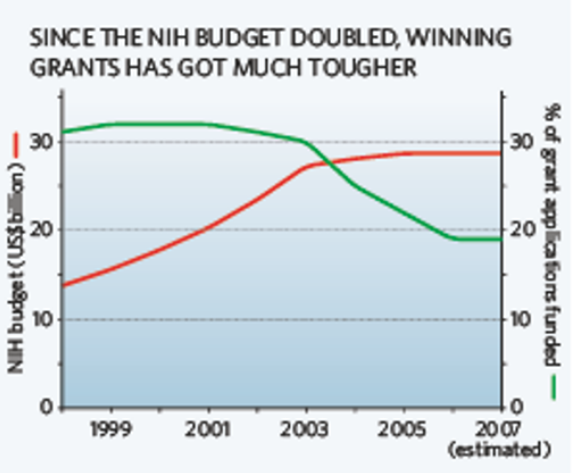

has fallen in real terms by $5.5 \%$ since the doubling ended in 2004.

"Nobody's bottom-line model showed funding decreasing after the doubling. We were talking about modest increases, not the floor falling out," says Tony Mazzaschi of the Association of American Medical Colleges (AAMC) in Washington DC.

In a speech at the neuroscience meeting, NIH institute heads acknowledged the inevitable outcome: the success rate for grant applications across the agency dropped from $31 \%$ in 1998 to $23 \%$ last year (see graph). Next year, this is expected to fall to $19 \%$. "We have really good grants that we can't afford to pay," says Story Landis, head of the National Institute of Neurological Disorders and Stroke.
${ }^{\alpha}$ The demand took off just as the NIH budget was landing."

With Congress highly unlikely to hand the NIH another significant increase in the near future, researchers and agency officials are considering how to adjust the funding system. Some are dubious that much pain can be avoided. "I personally don't see a terribly satisfying solution," says David Korn, former dean of the Stanford University School of Medicine in California and a top official at the AAMC who has studied the issue extensively.

Elias Zerhouni, the NIH director, is battling to counter that notion with a number of shortterm strategies, especially for first-time applicants and those fighting to get expiring grants renewed. ${ }^{\alpha} \mathrm{My}$ main concern is the individual investigator whose lab might close because of the gap in funding," he says. This year, Zerhouni cut all existing grants by $2.35 \%$, to free up money for new grants and grants competing for renewal. He will also use funds from expiring grants to gain a $3 \%$ boost in the number of new and competing grants awarded next year.

For some, these measures will be too little, too late. Rothstein says that he may have to lose staff and is already seeing "pruning "in other labs. His brother Jay, a cancer researcher at Thomas Jefferson University in Philadelphia,

\section{Funding agencies toughen stance on open access}

The Howard Hughes Medical Institute (HHMI), a non-profit research organization that funds more than 300 US researchers, is considering a plan to pressure its investigators into making their published papers freely accessible.

The plan, if approved, would dictate that publications must be deposited in a public database within six months of publication in order to count towards an inves tigator's application for reappointment. HHMI investigators ap ply for reappointment every five or seven years.

The proposal embodies the latest stage of the open-access movement: enforcement After years of requesting voluntary compliance, several funding agencies are considering tougher stances. In 2005, the US National Ins titutes of Health (NIH) asked grantees to voluntarily deposit articles in a public database such as PubMed Central within 12 months of publication. A year after the request, only $4 \%$ of $\mathrm{NIH}$ grantees had done so, prompting Congress to propose legislation mandating compliance.

Meanwhile, on 10ctober, Britain's Medical Research Council and the Wellcome Trustmedical charity began requiring grantees to deposit final, peer-reviewed manuscripts in public databases as soon as possible, but no later than within six months of publication. Failure to do so, says Wellcome Trust director Mark Walport, would be a breach of granting conditions.

HHMI president Thomas Cech says a decision on the proposed policy will probably be made inearly 2007. Although HHMI officials say they will not legislate where their investigators publish, several researchers say the threat of weakening their reappointment application represents significant pressure.

Cech says the proposed policy is simply anextension of $\mathrm{HHMI}$ guidelines about sharing published reagents and other research material. "The publications are the most useful product of our investigators' research," says Cech.

The HHMI is stillnegotiating with publishers, but Walport says most major journals, including Science and Nature, have complied with the Wellcome Trust's guidelines.

Mary publishers let authors pay to make their articles available immediately. For example, Wellcome Trust granteescan make their papers in most Elsevier journals publicly accessible for $\$ 3,000$ per article. Both the HHMI and the Wellcome Trustalready provide funds for publication in open-access journals. "We see payment to the publisher as part of the cost of research," says Walport. "And we're prepared to pay appropriately." 
Pennsylvania, will quit for the pharmaceutical company Amgen early next year, in part because of the struggle to get funding. $\mathrm{He}$ notes that few graduate students at his university plan to remain in academia: ${ }^{\alpha}$ People see how hard it is to run a lab."

After the NIH presentation at the neuroscience meeting, Peter Cariani spoke up. He studied spinal-cord regeneration at Tufts Medical School in Boston, Massachusetts, until his lab ran out of funding two months ago. He won applause for suggesting that the NIH should "make it harder for the rich to get progressively richer". Like others present, he feels that big labs hoover up too many grants, forcing teams like his out of the game. He wants the criteria for second and subsequent grants to be set higher than for an initial application.

Zerhouni cautions that such proposals put key research decisions into the wrong hands. "It would be very dangerous to dictate by bureaucratic fiat that somebody who is meritorious should not be funded because they have a grant or two. The peer reviewers are smart enough to know if someone is being overfunded or not."

He hopes scientists will stick out the hard times: "We still have the largest research budget on Earth: $\$ 28.6$ billion is larger than all other countries combined. If you believe in your research, don't give up on it. Things are not great. But they are not as desperate as some people portray them to be." Jim Giles and Meredith Wadman

But some publishers continue to struggle with the Wellcome Trust's requirement.

If a paper is available in a public database, this reduces the number of visits to subscription sites, says Mar tin Frank, executive director of the American Physiological Society.

Frank says this is why his society refuses to comply with the Wellcome Trust's guidelines. But such decisions may be more difficult with the proposed expansion of open-access requirements - Wellcome Trust-funded research accounts for only $2 \%$ of the papers in the society's 14 journals, but the NIH supports almost half.

Kathleen Case, publisher of the American Association of Cancer Research's five peer-reviewed journals, also considers the requirements too strict. "The Wellcome Trust asked us to change our policy and we said no," says Case. "And now we've been blacklisted."

Heidi Ledford

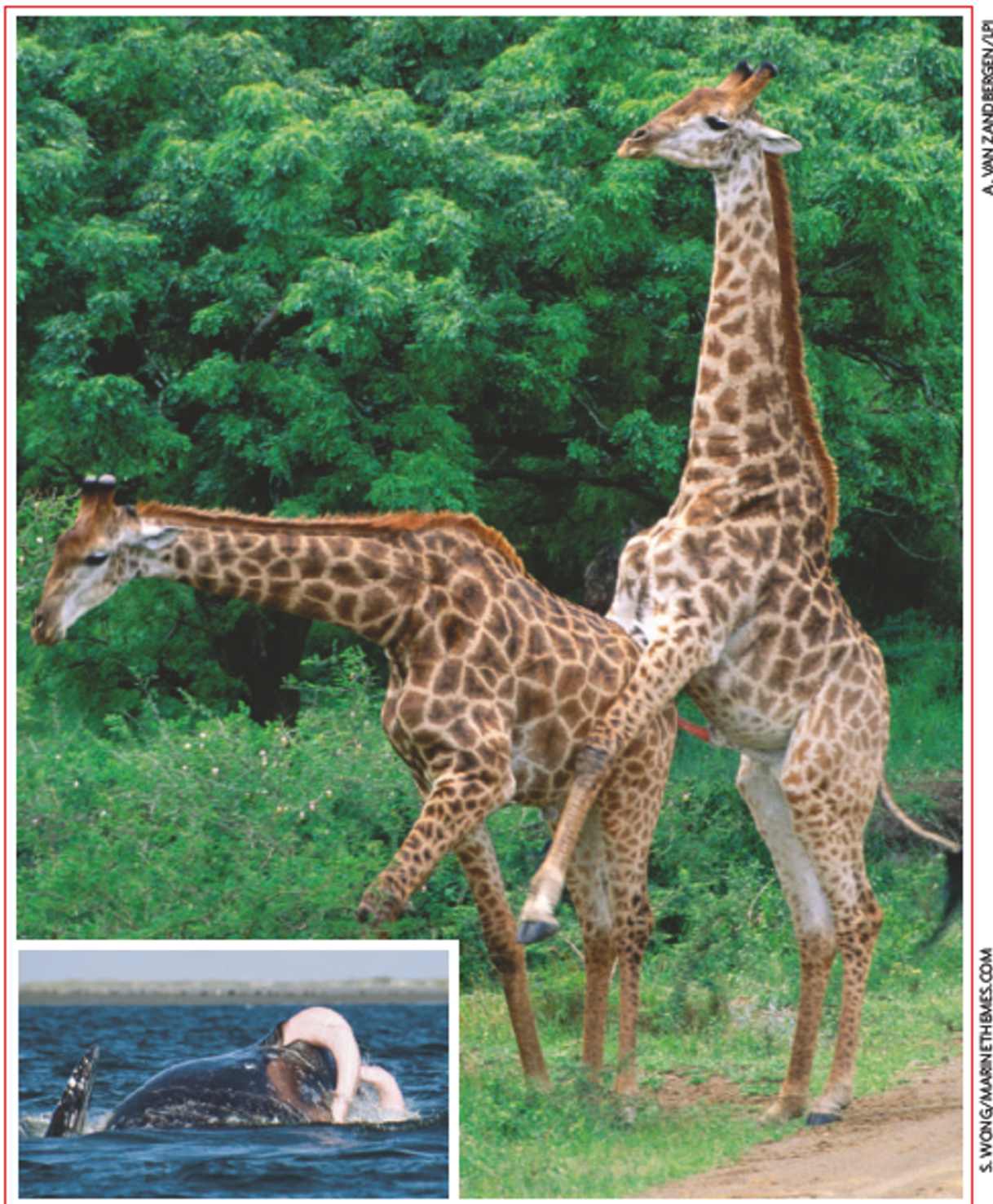

\section{SNAPSHOT \\ But is it natural?}

When Norway's museums authority called for ideas for an exhibition that engaged with contemporary societal debates, Geir Söli, head of exhibitions at Oslo's Natural History Museum, had just the theme. He had been listening to a priest arguing on the radio that homosexuality is a sin and contrary to nature.

People can only make up their minds about whether such behaviour is 'unnatural' if they know the cur rent state of researchon homosexuality in nature, he reasoned.

Nosooner had the authority approved his proposal than church groups began to protest against this use of public money. But Against Nature? AnExhibition on Animal Homosexuality opened peacefully at the Natural History
RAIN MAKES THE

GROUNDSHAKE

A wet weekend may be enough to set off an earthquake.

www.nature.com/news

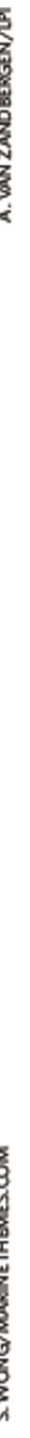

Museum on 12 October to wide acclaim. It will run until next August.

Söli focused the exhibition around 50 species, out of the 500 or so in which homosexual behaviour has been well documented. The exhibition comprises photographs, stuffed animals, models and other objects, along with explanatory text in Norwegian and English.

Two male giraffes are shown here indulging in roadside sex. Such encounters have been recorded in the literature as involving anal penetration and ejaculation. The insets hows two male whales (Eubalaenaaustralis) engaged in sexualgames.

Alison Abbott 